\title{
Formação docente e pesquisa inventiva: problematização, criação e intervenção nos cotidianos escolares
}

\author{
Angela Maria Dias Fernandes* \\ Eduardo Antonio de Pontes Costa*
}

\section{Resumo}

Este artigo propõe colocar em análise a relação entre formação docente e pesquisa interrogando as propostas formativas que intensificam processos disciplinadores, com foco em educadores e educandos como objetos de uma "educação pedagogizada", de uma compartimentalização dos saberes e de uma desarticulação entre esses e a cultura nas montagens curriculares. Nessa direção, a escola é valorizada como campo de lutas em que a pesquisa se caracteriza como práticas educativas questionadoras e inventivas. As discussões teóricas estão fundamentadas nos estudos de Varela (1994, 2002), Michel Foucault (2009), Silva e Moreira (2001), Zanella (2013) e Philippe Ariès (1978). Por fim, ao reconhecer a importância dos trabalhos desses autores como contribuições para o campo da educação, indicamos alguns caminhos para se pensar a formação dos professores e a pesquisa inventiva, concebendo a educação como um espaço de produção de diferentes saberes e sujeitos implicados com a idealização da crítica como movimento, criação e potência de vida.

Palavras-chave: Cotidiano escolar. Estudantes. Formação docente. Pesquisa.

\section{Introdução}

A reflexão que nos propomos aqui se alicerça na convicção de que a formação de professores não se constitui em mera repetição de saberes-fazeres pedagógicos produzidos a partir de um determinado a priori do pensamento científico moderno, de certo saber instituído que constitui um modo de ser professor e que se produz/

\author{
Recebido: 19/09/2015 - Aprovado: 27/02/2016 \\ http://dx.doi.org/10.5335/rep.v23i1.6358
}

Pós-doutor pelo Programa de Pós-Graduação em Psicologia da Universidade Federal de Santa Catarina. Professora Aposentada do Departamento de Psicologia e colaboradora do Programa de Pós-Graduação em Educação da Universidade Federal da Paraíba, Campus João Pessoa, Paraíba. E-mail: angeladfernandes@yahoo.com.br

** Doutor em Educação pelo Programa de Pós-Graduação em Educação da Universidade Federal Fluminense. Professor Associado do Departamento de Metodologia da Educação do Centro de Educação da Universidade Federal da Paraíba, Campus João Pessoa, Paraíba. E-mail: eduapcosta@bol.com.br 
reproduz no cotidiano da escola. Pensar a formação como campo de experimentação é rejeitar certos discursos hegemônicos que colocam a formação docente a partir de determinadas categorias individualizantes e universais. É recriar/criar outros modos de experimentar um "para quê" da educação, em especial, da formação docente, que aponte para questões sobre nós mesmos, sobre a nossa inserção na sociedade, na escola e sobre a nossa implicação com a própria história que se faz histórica na experiência (BENJAMIN, 1994).

A formação como campo de experimentação busca produzir (des)conexões com um modo de constituir sujeitos da educação (professor e aluno) que não se reduz ao processo ensino-aprendizagem (PIMENTA; ANASTASIOU, 2010). Isso implica pensarmos a formação por desvios, por intensidades e deslocamentos (DELEUZE, 1997) que apontem para pistas, saídas, para a constituição de uma formação docente tecida por um projeto coletivo de sociedade.

E o desafio está posto: Como produzir tensões diante de determinadas concepções de ser professor? Como desconstruir "verdades" hegemônicas que permitem falar apenas de um tipo de formação docente? E a questão das "expectativas" dos estudantes? Como confrontar a lógica disciplinarizadora de formação de educadores e educandos, objetos de uma educação "pedagogizada", produzindo sujeitos do conhecimento? Como articular potência de intervir e conhecimento "descolonizado" nos currículos escolares? Sendo a formação docente recorrente nas políticas educacionais, como pensá-la a partir de desvios, deslocamentos, bifurcações?

Nossa proposição consiste em pensar a relação entre formação e pesquisa problematizando e interrogando propostas formativas orientados pela tentativa de responder às questões dessa forma enunciadas. Essa é uma imprescindível tarefa, na medida em que os cursos de licenciatura buscam corresponder às demandas de um tipo de sociedade e de trabalhador que, frente a certo modelo hegemônico de educação, tem sempre se servido de mecanismos de disciplina e de controle.

A ideia que temos e assumimos nos remete a produzir campos de tensão e de problematização na pesquisa em educação, no sentido de recriar modos de constituir docentes como pesquisadores implicados (LOURAU, 1993) com sua própria prática. Esse caminho se faz intervindo e promovendo questionamentos às teorias e às práticas pedagógicas, às instituições escolares, com seus discursos normativos e prescritivos, historicamente produzidos por saberes e práticas que, tornando-os linguagens, se constituem com "estatuto de verdade" (FOUCAULT, 2009).

Desse modo, assumimos trilhar por um caminho teórico-metodológico que não produza "esquemas prontos", mas que aponte para um tempo cronológico de uma história descontínua, em específico, quando pensamos a formação docente em articulação com a produção do conhecimento. Nesses deslocamentos de olhares, de 
pensamentos, rejeitamos, como tão bem assinala Benjamin (1994), a repetição do passado pela criação do futuro, a partir do presente. Talvez sejamos como um ponto em movimento, algo que escapa, que guarda em si o poder da criação, que respira e produz potência, que se refaz a todo momento.

A pesquisa e a formação no cotidiano escolar, questões que norteiam este texto, reportam-nos à história da constituição da escola e ressaltam os processos que fizeram com que a investigação e a produção do conhecimento ocupassem um lugar secundário, e a disciplina, a hierarquia e a centralização dos saberes passassem a se impor como regra na educação e na sociedade. Nesse percurso, é fundamental verificar a concepção do que hoje poderemos considerar como sujeito do conhecimento. Tal exercício será feito, neste texto, por meio da articulação de três temáticas: a gênese da construção da escola como um espaço disciplinar; o olhar sobre a relação entre a pesquisa, o currículo e a articulação entre os saberes produzidos na escola; e a questão da pesquisa como intervenção no cotidiano escolar.

A investigação será realizada por meio de estudo teórico, problematizando as práticas educativas que valorizam a pesquisa em sala de aula como processo inventivo, produzindo e sendo produzida na articulação entre os saberes que circulam na escola. Igualmente, se processará uma investigação sobre a constituição dos sujeitos do conhecimento, que deriva das preocupações aqui anunciadas com relação à formação docente.

\section{A produção da escola como um espaço disciplinar}

Respondendo a uma necessidade de "organizar as populações", diante da possibilidade de acumular riquezas nas mãos dos que se lançavam ao novo mundo, à dominação de novos territórios, à mercantilização, a escola se constituiu a partir do renascimento como um espaço de disciplinamento, de triagem dos homens, de moralização, de manutenção dos bons costumes. Sobre isso, Foucault assinala:

Houve, durante a época clássica, uma descoberta do corpo como objeto e alvo de poder. Encontraríamos facilmente sinais dessa grande atenção dedicada então ao corpo - ao corpo que se manipula, se modela, se treina, que obedece, responde, se torna hábil ou cujas forças se multiplicam (2009, p. 117).

O autor utiliza uma figura arquitetônica construída no século XVIII para retratar os mecanismos da disciplina que se fazem presentes na escola, assim como em outros equipamentos disciplinares da sociedade. Esse seria o Panoptico de Benthan, que, inicialmente projetado para ser uma penitenciária, poderá representar o modelo disciplinar usado a partir desse século. "O panóptico é uma máquina de dissociar o par ver-ser visto: no anel periférico, se é totalmente visto, sem 
nunca ver; na torre central, vê-se tudo, sem nunca ser visto" (FOUCAULT, 2009, p. 191, grifo do autor). Segundo o referido autor, a vigilância constante faz com que os sujeitos passem a falar de determinadas verdades sobre eles mesmos, e, nesse processo disciplinar, os procedimentos de exame passam a produzir e a manter os corpos dóceis, domesticados e normalizados. "Somos submetidos pelo poder à produção da verdade e só podemos exercer o poder mediante a produção da verdade" (FOUCAULT, 2002, p. 28-29).

Foucault acrescenta que "[...] a disciplina é uma técnica de exercício de poder que foi, não inteiramente inventada, mas elaborada em seus princípios fundamentais durante o Século XVIII" (1979, p. 105). Na sequência de suas reflexões, o autor nos dá algumas pistas sobre como esse processo veio sendo produzido nas instituições do século XVIII e, particularmente, nas escolas: os sujeitos são distribuídos espacialmente (em classes, nas filas, e sob a vigilância de um professor); a disciplina não se interessa pelo resultado, mas pelo desenvolvimento do trabalho (o que está em foco é a maneira de adaptar melhor o sujeito, passo a passo); há uma vigilância perpétua e constante dos indivíduos; há um registro contínuo e um exame dos resultados que têm por meta a individualização (a identificação numérica, a nota individualizada e a fixação em uma turma).

Em seus estudos sobre o surgimento da escola, Philippe Ariès (1978) conclui que ela se organiza em articulação com um sentimento em relação às crianças e à infância, até então, desconhecido. O autor aponta que na Idade Média inicia-se um processo importante para a modernidade de individualização do sujeito, observado e passível de ser "civilizado".

No século XVII, para os jesuítas e toda a igreja católica, a escola deveria moralizar, disciplinar e educar as crianças (VARELA, 1994). A partir do século XVIII, a escola foi dividida, para atender às "necessidades" da hierarquização com base na origem social. O liceu, colégio ou secundário, passou a ser dirigido para os burgueses. A escola primária era a escola para o povo, com um ensino curto. Ariès associa o nascimento da burguesia ao surgimento da classe de idade e da classe social, quando afirma que "[...] ambas nasceram ao mesmo tempo, no fim do Século XVIII, e no mesmo meio: a burguesia” (1978, p. 194). Somente a partir do século XIX será observada uma correspondência mais rigorosa entre idade e classe na distribuição escolar, segundo menciona Ariès (1978, p. 177).

Divisões e hierarquizações afetam igualmente a constituição, a definição e o isolamento dos conhecimentos, principalmente a partir do século XVIII, quando irão regular o saber a ser valorizado na escola. Varela (1994) indica dois fenômenos que marcam esse processo: um denominado como "pedagogização do conhecimento" e outro, como "disciplinamento interno dos saberes". 
Varela (1994) observa, ainda, que, na modernidade, nasce uma nova forma de "conhecer" o mundo, que é isolando o conhecimento humano em áreas que não se tocam, criando-se fronteiras entre a História e a Geografia, a Filosofia e a Astronomia, entre os fatos e os lugares. Pedagogia, conforme o dicionário Aulete (2016), significa a "teoria e a ciência da educação". Pedagogizar seria, portanto, colocar o conhecimento a serviço (somente) de uma nova lógica, ou seja, a lógica da "ciência pedagógica". Esse processo, que vai surgindo lentamente na história da humanidade, significa a instauração de um novo ordenamento dos saberes, de acordo com os interesses moralizantes e disciplinadores da sociedade ditados, inicialmente, pela igreja católica e capitaneados pelos colégios jesuítas.

Como nos diz Varela (1994), o processo de pedagogização dos conhecimentos só se efetiva porque a escola dos jesuítas consegue expropriar os poderes detidos, até então, pelos estudantes, que passam a ser vistos como indefesos, para que a sociedade e a escola pudessem melhor discipliná-los. Essa autora continua sua observação sobre como os colégios dos jesuítas se relacionavam com os alunos, afirmando que, "[...] como fruto dessas expropriações, os estudantes perderam sua autonomia, suas prerrogativas ou, se quisermos, seus 'privilégios'; transformaram-se, assim, em colegiais, em escolares" (VARELA, 1994, p. 88).

Outro efeito importante da construção dos colégios dos jesuítas é o fato de que eles definiam quais saberes "verdadeiros" poderiam circular nas escolas e quais deveriam ser afastados, o que, posteriormente, foi determinando as bases da cultura dominante. É expressivo um último efeito citado por Varela (1994): para manter os saberes ordenados de acordo com a lógica pedagógica, que submete o estudante e o impede de produzir conhecimentos, foi necessário criar um aparato disciplinar. $\mathrm{E}$ foi dessa maneira "[...] que a disciplina e a manutenção da ordem nas salas de aula passaram a ocupar um papel central no interior do sistema de ensino até chegar praticamente a eclipsar a própria transmissão de conhecimentos" (VARELA, 1994, p. 89).

Vimos, portanto, que a indicação dos saberes que devem ser perpassados nas escolas e a submissão do estudante a esses saberes e aos mestres (ou professores de hoje) são produções históricas que foram dando significado à escola tal qual a conhecemos. As pedagogias disciplinadoras focalizam os sujeitos, enquadrando-os por meio da vigilância hierárquica e da sanção disciplinadora. Como vimos demonstrando, “[...] as pedagogias disciplinares implicam, portanto, novas relações de poder que são tanto menos visíveis quanto mais física e materialmente estão presentes e quanto mais vinculadas estão ao processo de aprendizagem" (VARELA, 2002, p. 86).

O segundo fenômeno observado por Foucault, e sublinhado por Varela (1994), ocorreu por uma tentativa do estado moderno de controlar os saberes que se encon- 
travam dispersos e colocá-los a seu serviço, isto é, a serviço do controle da sociedade pelo estado. Essa mesma autora ressalta, na obra de Foucault, quatro procedimentos que persistem na sociedade quando ela discrimina os conhecimentos passíveis de serem ministrados na escola: eliminar e desqualificar os saberes considerados pequenos ou inúteis; normatizar os saberes de modo a manter a comunicação entre os que são importantes e entre seus mestres; classificar hierarquicamente os saberes; centralizar os saberes em forma de pirâmide, situando os que são considerados mais importantes, no topo, e os menos importantes, abaixo (VARELA, 1994, p. 90).

Foucault (2002), investigando essa estruturação dos saberes ao longo dos tempos, aponta que existiu uma luta pela legitimidade científica, que representou um controle cada vez maior do conhecimento assim como a construção social de um novo tipo de sujeito, de homem moldado pela racionalidade e pela disciplina. Isso significa que a ciência moderna e os novos modos de produção do capitalismo exigiram um saber que se moldasse às necessidades da produção e de certo tipo de homem que se submetesse às normas.

A desqualificação dos "pequenos homens" ou do homem comum; o estabelecimento de normas de comportamento e de comunicação, de modo a fixar cada um em seu "lugar", impedindo a comunicação entre grupos sociais diferentes; a obediência às hierarquias e o reconhecimento do controle centralizado são as exigências que o capitalismo emergente dirige à escola. Para que esse processo, que desqualifica, normatiza e hierarquiza saberes e indica quais estão no centro, no comando, tenha "sucesso", é necessária a aceitação e a adesão dos homens. Foucault (2009) se refere ao processo de disciplinarização dos homens. A vigilância constante e a possibilidade da punição são práticas construídas nesse sentido.

$\mathrm{Na}$ história de constituição dos colégios, as práticas que visavam conseguir a obediência eram baseadas em castigos corporais, mas, com o passar do tempo, o poder do estado foi sendo interiorizado, fazendo parecer "natural" obedecer às ordens e às normas que visavam fazer a escola e a sociedade funcionarem, tornando os corpos escolarizados dóceis e úteis. Assim, os castigos corporais somem de cena ou, pelo menos, não são mais permitidos, e a vigilância vai sendo aprimorada (VARELA, 2002).

Relacionando os dois fenômenos - a pedagogização dos conhecimentos e o disciplinamento interno dos saberes ou dos conhecimentos -, verificamos que os mesmos procedimentos que modelam o saber irão modelar os sujeitos, constituindo o que Foucault denomina de sociedade disciplinar, e, por isso, a escola vai se tornando uma das principais instituições da sociedade. Essas instituições é que fornecerão o estatuto de cientificidade aos saberes por elas sancionados. Sobre esse aspecto, Varela conclui que "[...] o poder deixou de ser exterior aos sujeitos para fazer-se interior ao próprio processo de aprendizagem" (2002, p. 92). 
Verificamos, então, que estamos diante de um processo em que poderes se exercem produzindo o campo de conhecimentos úteis aos projetos disciplinadores da escola, que implicam operações de vigilância e normatização dos próprios sujeitos. A pesquisa educacional, se concebida como ato de produção do conhecimento, deverá partir da compreensão desse processo social. Portanto, é necessário intervir nos caminhos e nos procedimentos disciplinares e confrontá-los no sentido de produzir tensões, interrogações, frente a determinadas concepções de ser professor que, certamente, são cristalizadas nos saberes e fazeres pedagógicos que circulam no cotidiano escolar.

Inicialmente, é importante olhar criticamente para as práticas escolares que ainda se pautam na perspectiva de ordenamento, da classificação e da hierarquização do conhecimento a ser construído na escola, propondo novas formas de relacionar teoria e prática. Assumimos a ideia defendida por Varela (1994, p. 95), quando indica que uma importante pista é tentar a aproximação entre as teorias gerais do conhecimento e os saberes locais, ditos "menores", práticos, promovendo um inter-relacionamento entre eles.

Outro passo a ser dado é colocar em questão as práticas de submetimento do aluno, fazendo dele um estudante que investiga, que estranha a realidade e se compromete com a possibilidade de construir outras perguntas diante do mundo. No entanto, ao professor cabe construir esse caminho de diálogo com o novo conhecimento, recusando procedimentos hierárquicos e centralizadores. E como desconstruir "verdades" hegemônicas que permitem falar apenas de um tipo de formação docente? No enfrentamento dessa questão, indicada como importante nesta investigação, entendemos que assumir autonomia significa assumir a responsabilidade, ao invés de aceitar passivamente o que já está pronto. Não significa simplesmente recusar tudo o que aí está, mas tentar compreender os esquemas pedagogizantes e disciplinares que estão sendo usados para formular teorias e práticas propostas $a$ priori, para poder montar alternativas possíveis no sentido de também podermos desempenhar funções libertadoras (VARELA, 1994, p. 95).

Portanto, no espaço escolar, a pesquisa pode ter um grande impacto, no sentido de confrontar a perspectiva disciplinar que, comumente, caracteriza nossas escolas. A construção de práticas educativas que valorizem cotidianamente a pesquisa, igualmente, requer a constituição de um novo sujeito do conhecimento, que possa sustentar esse processo de crítica, construindo-se e, ao mesmo tempo, construindo a própria instituição escolar e a sociedade. Nesse caminho, é fundamental promover uma reflexão focalizando uma concepção de pesquisa que se articule com a crítica à organização curricular que, como temos apontado, está pautada na disciplinarização e na hierarquização dos conhecimentos. 


\section{A pesquisa, o currículo e a articulação entre saberes produzidos na escola}

Escapar dos sentidos cristalizantes que a escola indica é a linha a ser percorrida por aqueles que pensam a educação como um espaço de produção de sujeitos e de saberes implicados com a idealização da crítica como movimento, como criação, como potência de vida. Educar assume, assim, outra dimensão. Como nos indica Gallo (2008), não podemos reduzir a educação à transmissão de conhecimentos nem a uma lista de conteúdos a serem aprendidos. A educação e a instrução se complementam na formação integral de uma pessoa, processo que deve se dar intelectual e socialmente.

Essa formação acontece no cotidiano da escola, quando o estudante se relaciona com todos os outros atores sociais (professores, merendeiras, diretores, pais e comunidade). Para mediar as relações, apresenta-se o método pedagógico, que não se reduz a simples técnicas de ensino-aprendizagem, mas compreende o confronto individual e coletivo na construção do conhecimento, não necessariamente explicitado baseado na possibilidade de pensar e criar caminhos com autonomia. Para tanto, são indispensáveis três procedimentos: saber discriminar os conteúdos que estão presentes no cotidiano escolar, compreender como o poder se exerce nas construções curriculares e "mapear" como se articulam esses currículos com as posturas exigidas na escola (GALLO, 2008).

O desafio colocado no percurso que fizemos até este momento é, pois, o de montar as bases para a construção de uma perspectiva de pesquisar na escola como intervenção na lógica disciplinadora e hierarquizante que engessa os saberes e seus sujeitos. A investigação sobre as montagens curriculares nos parece um caminho produtivo, partindo da concepção do currículo ${ }^{1}$ como produção social ou, como indicam Silva e Moreira, "[...] um terreno de produção e de política cultural, no qual os materiais existentes funcionam como matéria-prima de criação, recriação e, sobretudo, de contestação e transgressão" (2001, p. 28). Avançando nessa formulação, Silva afirma que:

[...] o conhecimento e o currículo não são coisas, como a noção de "conteúdos" - tão estranhada no senso comum educacional - nos leva a crer. O conhecimento e o currículo corporificam relações sociais. Isto significa não apenas ressaltar seu caráter de produção, de criação, mas, sobretudo seu caráter social (2002, p. 64).

Essa pista é muito importante porque nos ajuda a pensar que nenhum saber ou currículo é desinteressado, do ponto de vista de seu compromisso social. Eles são construções sociais e devem ser considerados como historicamente produzidos em um jogo de forças presentes no cotidiano escolar. Compreendida dessa forma, a construção de um currículo crítico instaura um processo que permite confron- 
tar a lógica da formação disciplinarizadora, conforme proposto neste texto, sendo fundamental a valorização de elementos que reconheçam educadores e educandos - objetos de uma educação "pedagogizada" - como sujeitos do conhecimento que, ao se situarem diante das relações sociais, organizam as bases para a identificação e a constatação de sua própria historicidade.

Entendemos que desterritorializar o currículo é pensar em modos outros de resistir, de provocar fissuras, de produzir estranhamentos. Para Silva (2002), é necessário identificar nos currículos o discurso e os significados que dão corpo aos modelos de existir, pensar e agir dos grupos socialmente dominantes. Ele afirma que "[...] a educação, o currículo e a pedagogia estão envolvidos em uma luta em torno de significados" (2002, p. 68).

Essas reflexões nos encaminham para a possibilidade de formular a crítica aos currículos e aos materiais pedagógicos disponíveis e de reconhecer o caráter ideológico e político dos livros e dos métodos apresentados como oficiais. Na sequência desse caminhar, apresentamos, como necessária na formação crítica do sujeito, a constituição de novos materiais pedagógicos, estratégias de ensino e projetos curriculares. A construção de experiências que permitam a articulação entre os diversos saberes é, igualmente, um passo importante.

Estamos, portanto, diante de uma grande responsabilidade, e a questão que se coloca, com base nas contribuições de Silva (2002), é sobre como proceder, já que sempre se apresenta para nós um caminho "mais fácil" de assumir o livro didático pronto, a metodologia já programada, as soluções (repetidas e decoradas) de problemas que não se constituem como novas interrogações. Nossa resposta está na busca por nos tornarmos sujeitos de nossa prática e recusar a ideia de que um currículo é uma coleção de conteúdos reunidos de forma neutra. Para tanto, teremos que assumir que a seleção de materiais para a composição de um currículo é uma atividade social e política. Segundo Berticelli, na escolha de conteúdos, "põem-se em jogo interesses, exercita-se poder, determinam-se rumos políticos" (2005, p. 168).

Nesse caminho de tratar as montagens curriculares como prática social, reafirmamos a concepção de currículo como produção de sujeitos e de lugares sociais. Para tanto, trabalharemos com a noção de cultura, reafirmando que a escola tem um importante papel de ampliar as potencialidades humanas e participar da construção de subjetividades. Referimo-nos a todos os atores sociais que possam se fazer participantes da ação educativa como sujeitos a serem "afetados" - os professores, os estudantes e suas famílias, os funcionários e a comunidade.

Avançando nesta investigação, afirmamos que o currículo deve ser compreendido como um campo em que diversas forças concorrem, lutando para impor suas concepções. É nesse momento que Giroux e Simon (2001) qualificam a ação da pedagogia e do professor como fundamentais no confronto com a cultura hegemônica 
e recusam a prática de tornar a visão de mundo dominante como a única a reger o cotidiano escolar. Esse movimento pode ser alcançado quando, em uma experiência pedagógica, todos os sujeitos tenham a possibilidade e a oportunidade de expressar suas imagens, suas formas de conhecer o mundo e seus afetos.

Giroux e Simon (2001) propõem uma discussão importante para aprofundar a relação entre cultura popular e pedagogia. Estamos afirmando que a pedagogia se articula com a política cultural quando, por exemplo, coloca em questão a própria origem dos discursos preconceituosos dirigidos à cultura popular e os elimina, desqualificando-a como conteúdo científico; quando permite o ocultamento dos processos de exploração de uma classe social por outra; quando desvaloriza a vida pública e as lutas sociais.

Não se pode considerar que trazer a cultura para o contexto escolar e promover sua participação nos currículos sejam, simplesmente, uma introdução de “novos" conteúdos ou uma concessão aos "subordinados”. Essa ação precisa figurar como uma prática de poder que fará movimentar opiniões e lugares que os sujeitos, participantes do processo, ocupam no movimento incessante de disciplinarização e de resistência.

Costa (2005) afirma, e concordando com esse caminho de análise, que é fundamental que as escolas e seus currículos sejam analisados como espaços privilegiados da concretização da política de identidade. Seguindo com essa autora, veremos que ela reconhece que “[...] o currículo escolar é um lugar de circulação das narrativas, mas, sobretudo, é um lugar privilegiado dos processos de subjetivação, da socialização dirigida, controlada" (2005, p. 38).

Aqui, ao reforçar as análises e as críticas de Foucault, consideramos importante identificar outro regime, que o autor designou como sociedade de controle, que corresponde a um modo de subjetivação em que os indivíduos não são mais fixados, e sim controlados a "céu aberto" pelas novas tecnologias. A disciplina continua sendo alcançada por estratégias que permitem controlar a circulação dos sujeitos, no tempo e no espaço, mantendo a hierarquização, a classificação e a normatização. Nessa mesma direção, é possível afirmar que há uma lógica em tempos do Império na discussão sobre as sociedades disciplinares e de controle. Sob o ponto de vista de Pelbart,

O Império é uma nova estrutura de comando, em tudo pós-moderna, descentralizada e desterritorializada, correspondente à fase atual do capitalismo globalizado. [...]. O império coincide com a sociedade de controle, tal como Deleuze, na esteira de Foucault, a havia tematizado. Em substituição aos dispositivos disciplinares que antes formatavam nossa subjetividade, surgem novas modalidades de controle. Em lugar do espaço esquadrinhado pela família, escola, hospital, manicômio, prisão, fábrica, tão característicos do período moderno e da sociedade disciplinar, a sociedade de controle funciona através de mecanismos de monitoramento mais difusos, flexíveis, móveis, ondulantes, 'imanentes', incidindo diretamente sobre os corpos e as mentes [...] (2003, p. 81). 
Nesse contexto, a "lentidão" das escolas de hoje concorre com a pressa do mundo informatizado, mas, lado a lado, vem construindo um sujeito conformado com seu lugar social. Por isso, devemos estar atentos às novas montagens curriculares, sinalizando a perspectiva de que qualquer currículo, com intenções "bem endereçadas", é o resultado de uma relação de poderes que se exercem. Quando aproximamos currículo e cultura, poderemos produzir espaços em que verdades instituídas sejam problematizadas do ponto de vista das relações de classe e de interesse social.

Aqui, nos colocamos em posição de situar algumas propostas para que esse processo de formação social do aluno e de produção do saber implicado com as lutas sociais da humanidade aconteça no sentido de pensar outros modos de pesquisar como "[...] reinvenção de práticas a partir de uma realidade que mobiliza em cada pesquisador um universo de incertezas" (ZANELLA; FURTADO, 2012).

A pergunta que se reafirma é: Como, metodologicamente, poderemos garantir que, da instrumentalização dos alunos, como sinalizou Gallo (2008), irrompa um novo campo de possibilidades na construção do conhecimento? A pesquisa tomada como intervenção social é aqui sinalizada como um caminho. Trata-se de priorizar $o$ ato de perguntar, de inquirir, de questionar, de enfrentar a possibilidade de criar, de produzir conhecimento no chão da escola.

\section{Pesquisa como intervenção no cotidiano escolar}

Concordamos com René Lourau (1993) quando ele assinala que estamos todos implicados com a produção de conhecimento. Ao propor a recusa da noção de neutralidade posta na produção de diferentes saberes, vai nos falar do conceito-ferramenta de implicação e de pesquisa-intervenção como ações potentes em práticas de pesquisa. Ainda de acordo com esse autor, a ideia é pôr em análise determinados discursos e práticas que circulam e se reproduzem, em especial, no cotidiano escolar. Pôr em análise significa desnaturalizar, problematizar, determinadas 'verdades' que se instituem no chão da escola, a partir de um modo de saber-fazer pedagógico advindo e produzido por sujeitos experts através de seus especialismos. Desse modo e partindo dessas considerações, afirmamos, ainda, e com base em Rocha (2001), ser necessário que sujeitos escolares, a começar pelos professores, analisem a proposta do projeto curricular e as experiências de ensino da escola, observando que imagem de escola está sendo retratada e se ambos (projeto e práticas) estão servindo para o desenvolvimento do ideal democrático de autonomia do sujeito e da coletividade. 
Outra estratégia, segundo Rocha (2001), é a de atentar para os mecanismos que dificultam o engajamento dos sujeitos, no processo de construção de uma escola democrática. Ou seja, indagar de que forma a fragmentação e o não reconhecimento da diferença (entre os sujeitos) estão sendo fortalecidos no cotidiano da escola, nas relações entre os sujeitos e na construção do conhecimento.

Estamos afirmando, com isso, que o educador/pesquisador sensível à mudança, ao novo, precisa estar aberto ao reconhecimento de si, de suas possibilidades, humildemente disposto a ser indagado pelo objeto de sua curiosidade, de sua pesquisa. O sentido da mudança é a motivação para a transformação, e só poderá ser reconhecida com uma metodologia de trabalho que a favoreça. Esse necessita ser, na sala de aula, um movimento cotidiano. Assim como compreendem Deusdará e Rocha, também, em nossas práticas de pesquisa-intervenção nas escolas públicas, "[...] o desafio reside na abertura de um espaço-tempo, convocando permanentemente os envolvidos no processo de ensinar e aprender a interferir na produção do cotidiano" (2012, p. 374).

Nesta exposição, que valoriza a importância de reconhecermos a construção do sujeito do conhecimento e do objeto de forma histórica, socialmente inter-relacionada, nos deteremos mais detalhadamente a expor algumas repercussões fruto das aproximações entre a pesquisa inventiva e o cotidiano escolar, enunciando outra importante indagação: Como articular potência de intervir e conhecimento "descolonizado" nos currículos escolares? Em nossas pesquisas com professores nas escolas públicas, entendemos que isso implica investigar as condições/repercussões de ser educador/pesquisador, colocar a pergunta no lugar de elemento disparador da pesquisa e conectar intervenção, criação e problematização ao ato de investigar.

As concepções do educador-pesquisador implicado se deixarão transparecer por uma atitude inquieta e aberta a novas perguntas e a novos conhecimentos, que podem vir da inquietude do aluno, convidado a produzir, nesse processo, novos questionamentos. Quando se volta para seu trabalho de ministrar uma aula ou de aproximar um grupo de crianças, adolescentes ou jovens de um conhecimento ou de um objeto, o educador/pesquisador se abre ao diálogo e se oferece como um sujeito a ser construído nesse processo que ele criou, dinamizando seu grupo de alunos. Ghedin e Franco (2008, p. 143), quando apontam a reflexão sobre si como importante fundamento do processo investigativo, afirmam que, havendo um sentido no ato de conhecer e ao se buscar conhecer um dado objeto, não é este somente que se torna conhecido, porém, o próprio sujeito na condição de pesquisador.

Considerando esses fatores como inerentes ao ato de conhecer, podemos colocar que toda pergunta sinaliza uma escolha e revela o referencial teórico de quem a fez, seus valores e visão de mundo. Desse modo, como indicam Zanella e Sais 
(2008), é por meio da pergunta e da compreensão de sua natureza que o educador/ pesquisador descobrirá qual caminho trilhar para encontrar as respostas. Ao afirmar que toda pesquisa começa com uma pergunta, Zanella e Sais (2008, p. 682-683) indicam que cabe ao ser humano buscar entender a realidade, visando superar o conhecimento existente e produzir novas formas de relação com o mundo. Apontam para a importância da produção de relações estéticas, inventivas, pautadas no fato de sermos, ao mesmo tempo, unos e coletivos, indivíduos e grupos.

Abordamos, anteriormente, que é preciso promover uma formação social dos sujeitos envolvidos com a educação, de modo a alcançar uma integração ativa do homem à realidade. Isso se consegue quando o conhecimento é problematizado na sua utilização e na sua concepção. Reafirmamos que é necessário identificar o caráter político e social do processo de ensinar e aprender. Porém, isso só será possível se o ensino estiver baseado em perguntas (diversas) sobre o mundo, e não na "descoberta" e na repetição de respostas.

$\mathrm{O}$ educador-pesquisador, ao orientar o aluno em relação ao método, também lhe mostra uma forma de se posicionar frente à realidade. Nesse sentido, é importante que auxilie o educando a formular uma "boa pergunta", coerente ética e epistemologicamente com o conhecimento que se quer produzir, e desenhe seu melhor método. Igualmente, irá indicar as leituras possíveis a serem feitas acerca dos resultados encontrados criando condições para a formulação de novas interrogações, de novas perguntas.

Como afirma Kastrup, em sua análise sobre formação inventiva e o devir-mestre:

Não há uma forma-mestre, mas momentos em que as subjetividades do professor e do aluno se encontram. Por isso insisto que a discussão sobre a formação do professor não pode abrir mão da questão da política cognitiva que praticamos. Política que implica a ultrapassagem de nossa atitude recognitiva e que exige uma luta permanente contra o cognitivista que insiste em se instalar em nós (2005, p. 1287).

É importante que o educador/pesquisador esteja atento para o fato de que as respostas encontradas nesse caminho serão sempre passíveis de serem questionadas, incorporadas e refutadas. Zanella e Sais, refletindo sobre essa temática, referem que "a complexidade é inerente ao objeto de estudo da pesquisa" (2008, p. 683). Essa complexidade, segundo Ghedin e Franco (2008, p. 103), deve ser considerada como um elemento constitutivo do fenômeno educativo.

Partindo dessa reflexão, indicamos que, na atividade do educador/pesquisador, no ato de pesquisar, está impressa a possibilidade de intervir. $\mathrm{O}$ que se pode afirmar, nesse sentido, concordando com Zanella e Sais, é que "[...] toda pesquisa é uma intervenção, posto que ali se recriam sujeitos, conhecimentos e a própria 
realidade" (2008, p. 685). O educador deve propor aos educandos uma reflexão, assumindo junto com ele a posição de sujeitos da educação. Educador e educando, ao trilhar esse caminho, modificam-se, assim como modificam a realidade na qual estão imersos, produzindo novos significados sobre o conhecimento "dito pronto".

Zanella e Sais (2008, p. 685), ao abordarem a pesquisa como criação, propõem que se recuse a ideia de que o ato de criar seja concebido como um processo mágico, tranquilo. Segundo os autores, para que a pesquisa seja criação, é necessário conhecimento, técnica e sensibilidade. $O$ conhecimento diz respeito à compreensão da temática a ser investigada. A definição técnica e de procedimentos permite a construção de um campo de análise. Por fim, indicam a necessidade de uma abordagem sensível para se indagar e para compreender as complexas potencialidades das respostas que o ato de perguntar pode produzir nas pessoas e no mundo.

$\mathrm{O}$ ato de pesquisar implica uma invenção, assim como o ato de aprender. Essa é a visão que Cordeiro e Costa (2008) defendem e, com base em Foucault (1979), advertem:

Não há mais lugar para o intelectual com uma 'consciência representativa'. Em lugar dela, ele pergunta, 'quem fala e age?' e responde [...] sempre uma multiplicidade, mesmo que seja na pessoa que fala ou age. Nós somos todos pequenos grupos. Não existe mais representação, só existe ação: ação de teoria, ação de prática (2008, p. 130).

Afirmar o ato educativo, em uma perspectiva de ação crítica e inventiva, encerra nossa discussão, uma vez que coloca o educador-pesquisador diante de um processo coletivo de significação capaz de formar sujeitos e intervir na produção do conhecimento. Importante ressaltar que estamos aqui interessados em promover uma educação que perceba educadores e educandos envolvidos em um processo que produz formas de existir, pensar e agir, que possam transformar ações de disciplina em libertadoras, hierarquia em participação e respeito, desencanto pelo mundo em responsabilidade diante das dificuldades sociais.

Esse processo se afirma no cotidiano escolar, em um terreno político de forças sociais em luta. Assim, nos colocamos diante de nossa última questão: Sendo a formação docente recorrente nas políticas educacionais, como pensá-la a partir de desvios, de deslocamentos? De acordo com Kastrup,

[...] o desafio [como professor]não é capturar a atenção do aluno para que ele aprenda, mas promover nosso próprio aprendizado, do educador-pesquisador, da atenção às forças que irrompem e produzem um novo olhar sobre a prática docente, sobre o cotidiano escolar (2005, p. 1287).

Ao educador-pesquisador implicado cabe saber analisar esse terreno, no sentido de comprometer-se com novas práticas a serem inspiradas, pelo menos, em três indicativos, quais sejam: tratar os saberes como produto das sociedades e das 
lutas sociais e políticas, que os homens travam no sentido de promover resistência às tentativas de disciplinar o espírito criativo e inventivo do ser humano; ter como meta a formação social do educando e entender tal processo como a possibilidade de que cada aluno assuma, diante da sociedade, posturas de liberdade, respeito e responsabilidade; pautar sua prática na necessidade de identificar o caráter político e social do processo de construir, ensinar e aprender.

\section{Considerações finais}

$\mathrm{Na}$ articulação entre o conhecimento e a prática, cabe ao educador-pesquisador implicado discriminar os conteúdos, analisar sua produção histórica e verificar como o poder se engendrou nessas formulações. Aceitar o modelo pronto (o livro didático, os processos avaliativos centralizados) como a única possibilidade é mais "fácil", mas custa caro, do ponto de vista da formação de si próprio, como indivíduo singular que cresce na perspectiva de dialogar com o mundo. É nesse diálogo que se afirma a possibilidade de constituição de um educando que recuse o lugar de sujeito e objeto da neutralidade, posto pela "educação pedagogizada", afirmando-se como sujeito de seu processo de escolarização.

Assim, apontamos a necessidade de se assumir que uma base curricular e um projeto político-pedagógico localizado não ganham corpo sozinhos, mas se alimentam do trabalho vivo do educador e do esforço de sobrevivência do educando, no sentido de se fazer educar. Ao compreender uma montagem curricular como produto das relações sociais e de um jogo de forças, o educador implicado poderá buscar formas de fazer parte dessa história, na polissemia (BAKHTIN, 1992) dos saberes/fazeres pedagógicos.

Nesse processo, ao reconhecer o caráter ideológico dos métodos e dos currículos, o educador-pesquisador poderá trazer para a escola temas que orientem a experiência na sociedade. Interessados na constituição dos sujeitos historicamente alicerçados, dispostos à tarefa da criação, da invenção e da problematização, colocamo-nos em consonância com a afirmação de Zanella, quando, observando a dinâmica da atividade educativa, afirma que também:

[...] é condição para a docência a vivência intensa dos acontecimentos cotidianos pautada em uma sensibilidade atenta à diversidade, à diferença, ao supostamente inexpressivo, insignificante. Reconhecer possibilidades de sentidos silenciados, que não raros questionam os já consolidados (ZANELLA, 2013, p. 53).

Concluindo nossa contribuição para a construção de uma pedagogia sensível às diferenças e à potência de invenção de si e do outro, apontamos alguns passos que podem orientar o educador-pesquisador em seu percurso de intervir no coti- 
diano escolar, para aproximar formação e pesquisa: identificar os discursos e os significados que estão presentes nos currículos oficiais, nas propostas de ementas e nos programas; identificar, nos materiais pedagógicos propostos, quais os seus significados; selecionar temas que sejam pertinentes às discussões que a sociedade vem travando e que instrumentalizem os educandos para fazer frente às políticas e às práticas de submetimento; organizar esforços, no sentido de romper com a fragmentação entre os saberes e apontar para a construção de um saber global; fortalecer uma política cultural que coloque em questão a produção dos discursos preconceituosos dirigidos à cultura popular.

Por fim, outros caminhos devem ser criados na ressignificação da pesquisa como intervenção no cotidiano escolar. Nessa perspectiva, anuncia-se um modo de ser sujeito do conhecimento, em um conjunto de ações que valorizem e afirmem a expressão de suas imagens, de suas formas de conhecer o mundo e seus afetos, em confrontos e encontros com outras formas e outras sensibilidades.

\section{Teacher training and the inventive research: problematization, creation and intervention in the quotidian schools}

\section{Abstract}

This article proposes to think the relationship between the teacher training and the research, making question the training proposals that enhance disciplinary proceeding. Try to focus the pupil's production as object of the "pedagogized education", the division of the knowledge and disjoints themselves, and the curriculum culture. In this direction, the school in appreciated as a "battlefield" where the research can be characterized as a group of educational activities based in the problematization and inventive. Theoretical discussions are based on studies by Varela (1994, 2002), Michel Foucault (2009), Silva e Moreira (2001), Zanella (2013) and Philippe Ariès (1978). At last, it recognizes the importance of the work by authors as contributions to the area of education, we indicate some ways to think about the teacher training and the inventive research, understanding the education as a place of the production of subject and knowledges implied, to perceive the critic as movement, creation, aimed to potentialize multiple and diverse meanings.

Keywords: Research. School quotidian. Students. Teacher formation.

\section{Nota}

1 Importa pensar também a lógica do currículo a partir dos processos e produtos em circulação nas práticas e nos discursos presentes no cotidiano escolar, que remetem à ideia de pensar o currículo dentro da lógica da “educação maior”. Segundo Gallo, “[...] a educação maior é aquela instituída e que quer instituir-se, fazer-se presente, fazer-se acontecer. A educação maior é aquela dos grandes mapas e projetos” (2008, p. 64). 


\section{Referências}

ARIÈS, Phillipe. História social da infância e da família. Rio de Janeiro: Guanabara, 1978.

BAKHTIN, Mikhail. Estética da criação verbal. Tradução de M. ․ E. G. Gomes Pereira. São Paulo: Martins Fontes, 1992.

BENJAMIN, Walter. Obras escolhidas. Magia e técnica, arte e política. São Paulo: Brasiliense, 1994.

BERTICELLI, Ireno Antonio. Currículo: tendências e filosofia. In: COSTA, Marisa Vorraber (Org.). O currículo nos limiares do contemporâneo. Rio de Janeiro: DP\&A, 2005. p. 159-176.

CORDEIRO, Denise; COSTA, Eduardo Antonio de Pontes Costa. Caminhos investigativos para compreender os jovens pobres: da imagem estatística às análises de implicação. In: SCHEINVAR, Estela et al (Org.). Anais do 1 Ciclo de Conferências: políticas que produzem educação. Rio de Janeiro: Faculdade de Formação de Professores, 2008. p. 123-144.

COSTA, Marisa Vorraber. Currículo e política cultural. In: (Org.). O currículo nos limiares do contemporâneo. Rio de Janeiro: DP\&A, 2005. p. 37-68.

DELEUZE, Gilles. Crítica e clínica. Tradução de Peter Pal Pelbart. São Paulo: Editora 34, 1997.

DEUSDARÁ, Bruno; ROCHA, Marisa Lopes da Rocha. Cartografias da escola: controle e práticas de comunicação em análise. Psicologia \& Sociedade, Belo Horizonte, v. 24, n. 2, ago. 2012. Disponível em: <http://www.scielo.br/scielo.php?script=sci_arttext\&pid=S0102-71822012000200015\&ln $\mathrm{g}=$ pt\&nrm=iso $>$. Acesso em: 27 jul. 2016.

DICIONÁRIO AULETE. Pedagogia. Disponível em:<http://aulete.uol.com.br/site.php?mdl=aulete digital\&op=loadVerbete\&pesquisa=1\&palavra=pedagogia\&x=11\&y=16>. Acesso em: 27 jul. 2016 .

FOUCAULT, M. Em defesa da sociedade. São Paulo: Martins Fontes, 2002.

. Microfísica do poder. Rio de Janeiro: Graal, 1979.

. Vigiar e punir. 36. ed. Petrópolis: Rio de Janeiro, 2009.

GALLO, Sílvio. Transversalidade e educação: pensando uma educação não-disciplinar. In: ALVES, Nilva; GARCIA, Regina Leite (Org.). O sentido da escola. Rio de Janeiro: DP\&A, 2008. p. 15-36.

GHEDIN, Evando; FRANCO, Maria Amélia Santoro. Questões de método na construção da pesquisa em educação. São Paulo: Cortez, 2008.

GIROUX, Henry; SIMON, Roger. Cultura popular e pedagogia crítica: a vida cotidiana como base para o conhecimento curricular. In: MOREIRA, Antonio Flávio; SILVA, Tomaz Tadeu da (Org.). Currículo, cultura e sociedade. 5. ed. São Paulo: Cortez, 2001. p. 93-124.

KASTRUP, Virgínia. Políticas cognitivas na formação do professor e o problema do devir-mestre. Educação \& Sociedade, Campinas, v. 26, n. 93, p. 1273-1288, set./dez. 2005. Disponível em: <http://www.scielo.br/pdf/es/v26n93/27279.pdf>. Acesso em: 27 jul. 2016.

LOURAU, René. Análise institucional e práticas de pesquisa. Rio de Janeiro: Universidade do Estado do Rio de Janeiro, 1993. 
PELBART, Peter Pal. Vida capital. Ensaios de biopolítica. São Paulo: Iluminuras, 2003.

PIMENTA, Sônia Garrido; ANASTASIOU, Léa das Graças Camargo. Docência no ensino superior. 4. ed. São Paulo: Cortez, 2010. 279 p. (Coleção Docência em Formação).

ROCHA, Marisa Lopes da. Educação e saúde: coletivização das ações e gestão participativa. In: MACIEL, Ira Maria (Org.). Psicologia e educação: novos caminhos para a formação. Rio de Janeiro: Ciência Moderna, 2001. p. 213-229.

SILVA, Tomaz Tadeu da. Descolonizar o currículo: estratégias para uma pedagogia crítica. In: COSTA, Marisa Vorraber (Org.). Escola básica na virada do século: cultura, política e currículo. 3. ed. São Paulo: Cortez, 2002.

SILVA, Tomaz Tadeu da; MOREIRA, Antonio Flávio. Sociologia e teoria crítica do currículo: uma introdução. In: MOREIRA, Antonio Fláveio; SILVA, Tomaz Tadeu da (Org.). Currículo, cultura e sociedade. 5. ed. São Paulo: Cortez, 2001. p. 07-38.

VARELA, Julia. O estatuto do saber pedagógico. In: SILVA, Tomaz Tadeu da (Org.). O sujeito da educação - estudos foucaultianos. Petrópolis, RJ: Vozes, 1994. p. 87-96.

Categorias espaço-temporais e socialização escolar: do individualismo ao narcisismo. In: COSTA, Marisa Vorraber. Escola básica na virada do século: cultura, política e currículo. 3. ed. São Paulo: Cortez, 2002. p. 73-106.

ZANELLA, Andréa Vieira. Perguntar, registrar, escrever - inquietações metodológicas. Porto Alegre: Sulina, 2013.

ZANELLA, Andréa Vieira; SAIS, Almir Pedro. Reflexões sobre o pesquisar em Psicologia como processo de criação ético, estético e político. Análise Psicológica, Lisboa, v. 26, n. 4, out. 2008. Disponível em: <http://www.scielo.gpeari.mctes.pt/scielo.php?script=sci_arttext\&pid=S0870-82312008000400012\&lng=pt\&nrm=iso >. Acesso em: 27 jul. 2016.

ZANELLA, Andréa Vieira; FURTADO, Janaína Rocha. Resistir. In: FONSECA, Tânia Mara Galli; NASCIMENTO, Lívia Maria do; MARASCHINI, Cleci (Org.). Pesquisar na diferença: um abecedário. Porto Alegre: Sulinas, 2012. p. 205-206. 